\title{
Study on Colour Stability and Microencapsulation of Anthocyanin Pigment Extracted from Dragon Fruit Peel by Spray and Freeze Drying ${ }^{\dagger}$
}

\author{
Rahila Parveen S. ${ }^{1}$, R. Preetha ${ }^{1, *}$ \\ 1 Department of Food Process Engineering, SRM Institute of Science and Technology, Kattangulathur, Chennai, 603203, \\ India, Tel: 9176610351 \\ * Correspondence: preethar@ srmist.edu.in; \\ $\dagger$ Presented at International e-Conference on Bioengineering for Health and Environment (ICBHE 2020)
}

Received: 5.07.2020; Revised: 10.07.2020; Accepted: 12.07.2020; Published: 15.07.2020

\begin{abstract}
Dragon fruit is a popular fruit grown in Malaysia. It is well known for the rich nutrient contents, and it is commercially available worldwide. It is rich in anthocyanins and antioxidants. Dragon fruit is also an essential source of betacyanin, which serves as a red/purple pigment with antioxidative properties. The objective of the present work is to study the stability of natural colorant from dragon fruit peel. The crushed peel and water were taken in the ratio of 1:10 and was subjected to seven different types of extraction techniques such as microwave-assisted extraction, ohmic heating, ultrahigh-pressure homogenization, sonicator, supercritical fluid extraction, aqueous extraction, Soxhlet extraction. Out of the microwave-assisted extraction had the most Anthocyanin content, and it was used for further studies. The selected extract was filtered, and the stability of anthocyanin was examined at varying $\mathrm{pH}$ $(2 \ldots 10)$ and temperature $\left(60 \ldots 100^{\circ} \mathrm{C}\right)$. In addition to this, thermal stability $\left(80 \ldots 100^{\circ} \mathrm{C}\right.$ for $\left.150 \mathrm{~min}\right)$ was checked at a deferent time interval $\left(80\right.$ to $100^{\circ} \mathrm{C} \ldots 150 \mathrm{~min}$.). The microwave extract was used for the encapsulation process using maltodextrin, and soy protein isolate as carrier material with 1:4, 1:5 core to wall ratio by spray drying and freeze-drying techniques. The quality analysis, such as total anthocyanin content, encapsulation efficiency, color, water activity, bulk density, solubility, and moisture content, were analyzed of microencapsulated anthocyanin extract. This result showed that encapsulated dragon fruit peel (pitaya) powder could be used as a natural colorant in food applications.
\end{abstract}

Keywords: Dragon fruit peel (pitaya); Natural Pigment; Anthocyanin content; Thermal stability.

(C) 2020 by the authors. This article is an open-access article distributed under the terms and conditions of the Creative Commons Attribution (CC BY) license (https://creativecommons.org/licenses/by/4.0/).

\section{Funding}

This research received no external funding.

\section{Acknowledgments}

This research has no acknowledgment.

\section{Conflicts of Interest}

The authors declare no conflict of interest. 